ORAL-POSTER

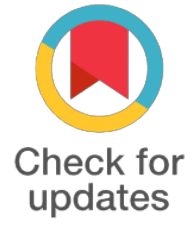

${ }^{*}$ For correspondence:

sudha.warrier@manipal.edu

Competing interests: The authors declare that no competing interests exist.

Received: 2017-04-30

Accepted: 2017-06-04

Published: 2017-09-05

Copyright The Author(s) 2017. This article is published with open access by BioMedPress (BMP).

This article is distributed under the terms of the Creative Commons Attribution License (CC-BY 4.0) which permits any use, distribution, and reproduction in any medium, provided the original author(s) and the source are credited.

\section{Human mesenchymal stem cell derived model of Alzheimer's disease - effect of Wnt antagonism in neurodegeneration}

\author{
Manasi Patil, Sudha Warrier \\ School of Regenerative Medicine, Manipal University, Bangalore 56006, India
}

Alzheimer's disease (AD), one of the most common types of dementia, is a serious and increasing health problem. This progressive disorder is manifested by loss of memory which worsens over time. Although several causative mechanisms for AD has been identified, the specific molecular mechanisms for the onset and progression of the disease has not yet been elucidated. This is mainly because of the lack of patient tissue at various stages of disease, in order to test and ascertain the molecular progression of AD. To address this lacuna, we have developed a human stem cell model of $A D$, derived from mesenchymal stem cells (MSCs) of perinatal tissues. We first derived cells of the central nervous system (CNS) from MSCs and then subjected them to AD specific neurodegeneration. Onset of neurodegeneration was ascertained by accumulation of BACE, nAChAR and presenilin. Neuronal generation was first established for expression neuronal specific markers such as nestin, Tuj1, Pax6, Sox1 and 2 by immunocytochemistry and quantitative RT-PCR. In the AD model thus established, we analysed further for the role of Wnt antagonists, $\mathrm{SFRP}_{3}$ and 4 and deciphered a link between inhibition of the Wnt-b catenin pathway and the onset of neurodegeneration. These studies would pave the way for the development of specific biomarkers for progression of $A D$ and novel drug targets based on these biomarkers.

\section{Keywords}

Alzheimer's disease, mesenchymal stem cells, Wnt antagonist, sFRP

Funding

References 